\title{
Assessment of subclinical atherosclerosis with ankle-brachial index in psoriatic arthritis: A case-control study
}

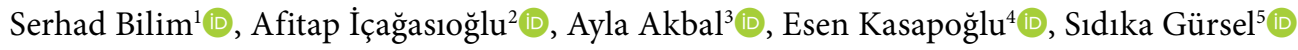 \\ ${ }^{1}$ Department of Physical Medicine and Rehabilitation, Division of Pain Medicine, Marmara University Faculty of Medicine, Istanbul, Turkey \\ ${ }^{2}$ Department of Physical Medicine and Rehabilitation, Istanbul Medeniyet University Göztepe Training and Research Hospital, Istanbul, Turkey \\ ${ }^{3}$ Department of Physiotherapy and Rehabilitation, Istanbul Bilim University, Istanbul, Turkey \\ ${ }^{4}$ Department of Internal Medicine, Division of Romatology, Istanbul Medeniyet University, \\ Göztepe Training and Research Hospital, Istanbul, Turkey \\ ${ }^{5}$ Department of Cardiovascular Surgery, Istanbul Medeniyet University Göztepe Training and Research Hospital, Istanbul, Turkey
}

\begin{abstract}
Objectives: This study aims to evaluate subclinical atherosclerosis using the Ankle-Brachial Index (ABI) in patients with psoriatic arthritis (PsA). Patients and methods: This case-control study included 51 PsA patients (24 males, 27 females; median age 47; range, 41 to 52 years) recruited at our hospital's outpatient clinics between October 2016 and January 2017 and 50 healthy controls ( 24 males, 26 females; median age: 48.5 ; range, 40.7 to 56 years). Anthropomorphic measurements and laboratory results were recorded. In patients, the 66 swollen/68 tender joints count, dactylitis score, Leeds Enthesitis Index, Health-related Quality of Life, the Psoriasis Area and Severity Index, and Dermatology Life Quality Index were evaluated. Ankylosing Spondylitis Quality of Life and Bath Ankylosing Spondylitis Disease Activity Index were applied to patients with axial disease. Then, Composite Psoriatic Disease Activity Index was determined. A Doppler probe and a standard blood pressure cuff were used to calculate the $A B I$ values for each participant.

Results: Patients had lower right $A B I$ (median, 1.05 vs. 1.1, $p<0.01)$, lower left $A B I(1.04$ vs. $1.09, p<0.01)$ and lower overall $A B I(1.03$ vs. $1.09, p<0.01)$ compared with healthy subjects. Twelve (23.5\%) patients had borderline $A B I$, but none of the controls $(p<0.01)$. Patients with borderline $A B I$ had a longer duration of psoriasis ( $25 \mathrm{vs}$. 15 years, $\mathrm{p}=0.03$ ). The distribution of borderline $\mathrm{ABI}$ value was statistically significant between patients with axial disease and peripheral disease only $(42.1 \%$ vs. $12.5 \%, p=0.02)$. Disease activity was found as an independent risk factor for borderline $A B I$ in a binary logistic regression (odds ratio $6.306,95 \%$ confidence interval 1.185 to $33.561, p=0.031$ ).
\end{abstract}

Conclusion: Lower ABI was found in PsA patients than healthy controls even in those matched with traditional cardiovascular risk factors. All participants with borderline $A B I$ were in the patient group. Borderline $A B I$ was associated with disease activity and disease duration. Keywords: Ankle-Brachial Index, atherosclerosis, cardiovascular disease, peripheral artery disease, psoriatic arthritis, spondyloarthropathy.

Psoriatic arthritis (PsA) is defined as an inflammatory arthritis associated with psoriasis. ${ }^{1}$ PsA is a member of the spondiloarthropaties together with ankylosing spondylitis, reactive arthritis, and enteropathic arthritis. ${ }^{2}$ The prevalence of arthritis in patients with psoriasis has been reported to be between 7 to $42 \% .^{3,4}$ However, arthritis may appear in up to $15 \%$ of patients before psoriasis. ${ }^{5}$

Besides joint involvement, PsA affects the cardiovascular (CV) system. ${ }^{6}$ Gladman et al. ${ }^{7}$ followed patients with PsA prospectively from

Received: February 24, 2020 Accepted: August 11, 2020 Published online: January 14, 2021

Correspondence: Serhad Bilim, MD. Marmara Üniversitesi Tıp Fakültesi, Fiziksel Tıp ve Rehabilitasyon Anabilim Dalı, Ağrı Bilim Dalı, 34899 Kaynarca, Pendik, İstanbul, Türkiye. Tel: +90 537 - 2685995 e-mail: dr.serhadbilim@gmail.com

\section{Citation:}

Bilim S, İcağasıoğlu A, Akbal A, Kasapoğlu E, Gürsel S. Assessment of subclinical atherosclerosis with ankle-brachial index in psoriatic arthritis: A case-control study. Arch Rheumatol 2021;36(2):210-218.

(2021 Turkish League Against Rheumatism. All rights reserved.

This is an open access article under the terms of the Creative Commons Attribution-NonCommercial License, which permits use, distribution and reproduction in any medium, provided the original work is properly cited and is not used for commercial purposes (http://creativecommons.org/licenses/by-nc/4.0/). 
1978 to 2004 . Hypertension in $18.8 \%$, myocardial infarction in $5.8 \%$, angina in $3.2 \%$, congestive heart failure in $1.7 \%$, and cerebrovascular accident in $0.8 \%$ of patients with PsA registered in the database were recorded. They stated that these findings were higher than general population.

However, this relationship has not been fully explained by the prevalence of traditional CV risk factors among PsA patients and underlying mechanisms have not yet been entirely understood. Assessment of the association between PsA and subclinical atherosclerosis, an early predictor of $\mathrm{CV}$ disease, is an emerging area of interest both for early diagnosis and for clarification of the relationship between $\mathrm{CV}$ disease and PsA.

Several studies have been conducted in PsA to evaluate subclinical carotid artery atherosclerosis which is known to be associated with an increased $\mathrm{CV}$ risk. It has been reported that patients with PsA have accelerated atherosclerosis irrespective of known $\mathrm{CV}$ risk factors. ${ }^{8-10}$

The Ankle-Brachial Index (ABI) is a method that is used to evaluate subclinical target organ atherosclerosis. ABI is also a validated method used in rheumatologic diseases to detect subclinical target organ atherosclerosis. ${ }^{11}$ Previously, ABI has been studied in diseases such as rheumatoid arthritis, ${ }^{12-15}$ systemic lupus erythematosus, ${ }^{16-18}$ Sjögren's syndrome, ${ }^{19}$ inflammatory bowel diseases,${ }^{20}$ and scleroderma. ${ }^{21-23}$

To the best of our knowledge, there is no study comparing the $\mathrm{ABI}$ values between PsA and healthy controls. Since ABI is easy to evaluate in clinical practice, it can be used as a screening tool for the detection of atherosclerosis in PsA. Therefore, in this study, we aimed to evaluate subclinical atherosclerosis using the $\mathrm{ABI}$ in patients with PsA.

\section{PATIENTS AND METHODS}

In this case-control study, 51 patients (24 males, 27 females; median age 47; range, 41 to 52 years) with a diagnosis of PsA according to the Classification for PsA criteria ${ }^{24}$ were recruited at Istanbul Medeniyet University Goztepe Training and Research Hospital Rheumatology Outpatient Clinics between October 2016 and January 2017. We used the G*Power version 3.1 software (Heinrich-Heine Universität Düsseldorf, Düsseldorf, Germany) to calculate the sample size. Prior data we achieved from our patients indicated that the difference in the response of matched pairs was normally distributed with standard deviation of 0.48 and the true difference in the mean response of matched pairs was 0.21 . If the change in the $\mathrm{ABI}$ was predicted to be at least $20 \%$, the number of patients included in the study should be 44 in each group to meet an $\alpha=0.05$ and a power $=0.80$. When $15 \%$ possible dropouts were assessed, 50 patients in each group should be included into the analysis.

The inclusion criteria were determined as patients diagnosed for at least six months and aged 18 to 65 years. Patients who were already diagnosed with peripheral arterial disease were excluded. Other exclusion criteria were determined by considering conditions that may cause atherosclerosis in peripheral arteries. Therefore, patients with diabetes mellitus, impaired liver or kidney function, a history of coronary vascular disease (such as angina, stable coronary artery disease, myocardial infarction, atrial fibrillation, surgery for ischemic heart disease), history of cerebrovascular disease (such as stroke, transient ischemic attack), chronic lung diseases (such as chronic obstructive pulmonary disease), and uncontrolled hypertension (diastolic blood pressure above $110 \mathrm{mmHg}$ or systolic blood pressure above $180 \mathrm{mmHg}$ ) were excluded. Patients with neurological or psychological disorders and patients who refused to participate were also excluded.

Fifty control healthy subjects (24 males, 26 females; median age 48.5; range, 40.7 to 56 years) matched by age and sex were recruited among healthy volunteers. The only inclusion criterion was signing the informed consent. Aforementioned exclusion criteria also applied for controls.

The study protocol was approved by the Istanbul Medeniyet University Goztepe Training and Research Hospital Ethics Committee (No: 2016/0208). A written informed consent was obtained from each participant. The study was conducted in accordance with the principles of the Declaration of Helsinki.

Data for this study were collected via interviews, physical examination, and laboratory 
tests. Information on age, history of illnesses and medical conditions and smoking habits was recorded. Anthropomorphic measurements including body weight and height were obtained and body mass index (BMI) was calculated. Waist circumference and laboratory tests such as fasting blood glucose, C-reactive protein (CRP), lipid profile, erythrocyte sedimentation rate (ESR), and renal and liver functions tests were noted.

Psoriatic arthritis patients who had peripheral arthritis before or at the time of physical examination without axial involvement were considered as having a pattern of peripheral disease only. PsA patients who had inflammatory arthritis of the spine determined by X-ray and magnetic resonance imaging with or without peripheral joint involvement were considered as having axial disease.

We used the Composite Psoriatic Disease Activity Index (CPDAI) which includes five domains: skin, dactylitis, enthesitis, peripheral joints, and spinal manifestations. ${ }^{25}$ To calculate the CPDAI score, the 68 tender/66 swollen joint counts, Health Assessment Questionnaire, Dermatology Life Quality Index, Psoriasis Area and Severity Index, dactylitis count, and Leeds Enthesitis Index were examined. Ankylosing Spondylitis Quality of Life and Bath Ankylosing Spondylitis Disease Activity Index were also used to assess disease activity and quality of life in axial disease group. ${ }^{26}$

These five different domains were scored separately and total scores were obtained. Based on CPDAI, patients with a score of 5 or less were considered to have minimal disease activity (MDA) and a score above 5 indicated active disease status. ${ }^{27}$

The American Heart Association (AHA) and the American College of Cardiology (ACC) Foundation revised the cutoff values for normal and abnormal ABI based on the results of Ankle Brachial Index Collaboration studies in 2011. ${ }^{28}$ ABI should be reported with abnormal values of 0.90 or less, borderline 0.91 to 0.99 , normal 1.00 to 1.40 , and non-compressible defined as greater than $1.40 .{ }^{28}$

After $15 \mathrm{~min}$ of rest in the supine position, systolic blood pressures (SBPs) of brachial arteries, posterior tibial arteries, and dorsalis pedis arteries in both arms and ankles were measured with a blood pressure cuff and a Doppler probe (ES-101EX EchoSounder ${ }^{\circledR}$, Koven Technology Inc., St. Louis, Missouri USA) for each participant under the supervision of the $\mathrm{CV}$ surgeon.

For calculation of right $\mathrm{ABI}$, the higher of right dorsalis pedis artery SBP and right posterior tibial artery SBP measurements were divided by the higher of the two brachial artery SBP values. Left $A B I$ was calculated in the same way. Lower of the right and left $\mathrm{ABI}$ was considered as overall ABI. ABI results were interpreted according to the cut-off values revised by AHA and ACC Foundation. ${ }^{28}$

\section{Statistical analysis}

Statistical analysis was performed using the IBM SPSS 24.0 (IBM Corp., Armonk, NY, USA) software. To test the normality of data within groups, all continuous variables were analyzed by the Shapiro-Wilk test. All values were shown as mean \pm standard deviation or medians and interquartile ranges, respectively, depending on the demonstration of normality. Comparison of the quantitative variables within or between groups was performed using the Student's t-test or the Mann-Whitney U test. Categorical variables were summarized by frequencies and percentages. Comparison of the qualitative variables was performed with the Pearson's Chi-square or the Fisher's exact tests according to fulfillment of assumption requirements. The magnitude of the associations between the borderline $\mathrm{ABI}$ and duration of psoriasis and PsA, disease activity, age, and PsA patterns were quantified by binary logistic regression models that provided the estimates of the odds ratios (OR) $(p<0.05)$.

\section{RESULTS}

Waist circumference, height, weight, BMI, and smoking habits were comparable between the patient and control groups (all p>0.05) (Table 1).

In terms of laboratory findings, there were no statistically significant differences in the fasting glucose and blood lipid profile between the groups, except for ESR and CRP which were significantly higher in patient group (Table 2).

Thirty-two $(62.7 \%)$ patients had a pattern of peripheral disease only and 19 (37.8\%) patients 
Table 1. Characteristics of psoriatic arthritis patients and healthy controls

\begin{tabular}{|c|c|c|c|c|c|c|c|c|c|c|c|}
\hline & \multicolumn{5}{|c|}{ Patient group $(\mathrm{n}=51)$} & \multicolumn{5}{|c|}{ Control group $(n=50)$} & \multirow[b]{2}{*}{$p$} \\
\hline & $\mathrm{n}$ & $\%$ & Mean \pm SD & Median & IQR & $\mathrm{n}$ & $\%$ & Mean \pm SD & Median & IQR & \\
\hline Age (year) & & & & 47 & $41-52$ & & & & 48.5 & $40.7-56$ & 0.74 \\
\hline $\begin{array}{l}\text { Sex } \\
\text { Female }\end{array}$ & 27 & 53 & & & & 26 & 52 & & & & 0.9 \\
\hline Height $(\mathrm{cm})$ & & & $165.9 \pm 8.1$ & & & & & $166.1 \pm 8.2$ & & & 0.91 \\
\hline Weight $(\mathrm{kg})$ & & & $77.5 \pm 10.5$ & & & & & $75.7 \pm 10.9$ & & & 0.49 \\
\hline Body mass index $\left(\mathrm{kg} / \mathrm{m}^{2}\right)$ & & & $28.1 \pm 4.5$ & & & & & $27.5 \pm 3.6$ & & & 0.51 \\
\hline Waist circumference $(\mathrm{cm})$ & & & $96.6 \pm 11.8$ & & & & & $95 \pm 9.2$ & & & 0.43 \\
\hline Smoking (ever or current) & 26 & 51 & & & & 23 & 46 & & & & 0.6 \\
\hline
\end{tabular}

had axial disease. Based on the CPDAI, 15 of 51 (29.4\%) patients had active disease while 36 (70.1\%) patients had minimally active disease. Other clinical features and current drug treatments of the patients are shown in Table 3.

None of the subjects were found to have abnormal $(\leq 0.9)$ or non-compressible $(>1.4) \mathrm{ABI}$ values in patient and control groups. Twelve subjects had borderline ABI (0.91 to 0.99) and all of them were in the patient group. Remaining 89 subjects had normal ABI (1 to 1.4). This distribution was statistically significant $(p<0.01)$. Right, left, and overall ABI values were significantly lower in the patient group compared to the control group (Table 4).

Demographic features and laboratory findings of patients with borderline $\mathrm{ABI}$ and those with normal ABI were compared. Differences between groups were not statistically significant ( $p>0.05)$ (Table 5). The median age of patients with borderline $\mathrm{ABI}$ was higher than patients with normal $\mathrm{ABI}$, while the difference was not statistically significant (51 vs. 46 years, $p=0.19$ ).

The duration of psoriasis was longer in patients with borderline $\mathrm{ABI}$ vs. patients with normal $\mathrm{ABI}$ and the difference was statistically significant (25 [15 to 37] vs. 15 [7 to 23] years, $\mathrm{p}=0.03$ ). Patients with borderline ABI had a longer duration of PsA. However, this result was not statistically significant. When $\mathrm{ABI}$ values were examined according to the pattern of the disease, $12.5 \%$ of patients with peripheral disease had borderline ABI, while $42.1 \%$ of patients with axial disease had borderline ABI $(p=0.02)$. However,

Table 2. Laboratory findings of psoriatic arthritis patients and healthy controls

\begin{tabular}{|c|c|c|c|c|c|c|c|}
\hline & \multicolumn{3}{|c|}{ Patient group $(\mathrm{n}=51)$} & \multicolumn{3}{|c|}{ Control group $(n=50)$} & \multirow[b]{2}{*}{$p$} \\
\hline & Mean \pm SD & Median & IQR & Mean \pm SD & Median & IQR & \\
\hline Fasting glucose (mg/dL) & $91.3 \pm 12.4$ & & & $93.02 \pm 9.2$ & & & 0.42 \\
\hline Total cholesterol (mg/dL) & & 47 & $40-61$ & & 50.5 & $40.7-60$ & 0.87 \\
\hline HDL cholesterol (mg/dL) & & 121 & $103-143$ & & 114.5 & $92-144.75$ & 0.54 \\
\hline LDL cholesterol (mg/dL) & & 106 & $86-143$ & & 120.5 & 87.5-182 & 0.51 \\
\hline Triglycerides (mg/dL) & & 196 & $177-225$ & & 187 & $166.75-231.75$ & 0.82 \\
\hline $\operatorname{ESR}(\mathrm{mm} / \mathrm{h})$ & & 17 & $12-41$ & & 14 & $8-23.3$ & 0.03 \\
\hline CRP (mg/dL) & & 0.3 & $0.1-0.7$ & & 0.1 & $0.1-0.2$ & $<0.01$ \\
\hline
\end{tabular}


Table 3. Clinical features of psoriatic arthritis patients $(\mathrm{n}=51)$

\begin{tabular}{lccc}
\hline & $\mathrm{n}$ & $\%$ & Mean \pm SD \\
\hline $\begin{array}{l}\text { Disease duration } \\
\quad \text { Psoriasis }\end{array}$ & & & $17.6 \pm 7.3$ \\
$\quad$ Psoriatic arthritis & & & $8.7 \pm 11.4$ \\
Disease pattern & & & \\
$\quad$ Peripheral disease only & 32 & 62.7 & \\
$\quad$ Axial disease & 19 & 32.8 & \\
Disease activity & & & \\
$\quad$ Minimal disease activity & 36 & 70.6 & \\
$\quad$ Active disease & 15 & 29.4 \\
Current treatment & & & \\
$\quad$ NSAIDs only & 6 & 11.8 & \\
$\quad$ cDMARDS & 29 & 56.8 \\
$\quad$ bDMARDs & 12 & 23.5 \\
$\quad$ cDMARDs + bDMARDs & 4 & 7.8 \\
\hline
\end{tabular}

SD: Standard deviation; bDMARDs: Biologic disease-modifying antirheumatic drugs; cDMARDs: Conventional disease-modifying antirheumatic drugs; NSAIDs: Nonsteroidal anti-inflammatory drugs. the disease duration of PsA was longer in patients with axial disease than in patients with peripheral disease only. This longer disease duration was also statistically significant (10 [6 to 18 ] vs. five [3 to 8] years, $\mathrm{p}=0.03$ ). Fifteen patients had active disease and eight $(53.3 \%)$ of these patients had borderline ABI. However, four (11.1\%) of the patients with MDA had borderline $\mathrm{ABI}$. The relationship between disease activity and borderline $\mathrm{ABI}$ distribution was statistically significant $(p<0.01)$. There was no statistically difference in current drug treatments between patients with normal $\mathrm{ABI}$ and borderline ABI (Table 6).

A binary logistic regression was performed to determine the independent predictors of borderline ABI values. The possible factors for subclinical atherosclerosis such as duration of psoriasis and PsA, age, disease pattern, and disease activity were entered into the logistic

Table 4. Comparison of Ankle-Brachial Index values

\begin{tabular}{|c|c|c|c|c|c|c|c|c|c|}
\hline & \multicolumn{4}{|c|}{ Patient group $(\mathrm{n}=51)$} & \multicolumn{4}{|c|}{ Control group $(n=50)$} & \multirow[b]{2}{*}{$p$} \\
\hline & $\mathrm{n}$ & $\%$ & Median & IQR & $\mathrm{n}$ & $\%$ & Median & IQR & \\
\hline Subjects with/borderline ABI & 12 & 23.5 & & & 0 & 0 & & & $<0.01$ \\
\hline Right ABI & & & 1.05 & 1.01-1.09 & & & 1.1 & $1.05-1.13$ & $<0.01$ \\
\hline Left ABI & & & 1.04 & 1-1.09 & & & 1.09 & $1.06-1.13$ & $<0.01$ \\
\hline Overall ABI & & & 1.03 & $1-1.08$ & & & 1.09 & $1.04-1.11$ & $<0.01$ \\
\hline
\end{tabular}

Table 5. Comparison of demographic features and laboratory findings among psoriatic arthritis patients with borderline and normal Ankle-Brachial Index values

\begin{tabular}{|c|c|c|c|c|c|c|c|c|c|}
\hline & \multicolumn{4}{|c|}{ Patient group $(\mathrm{n}=51)$} & \multicolumn{4}{|c|}{ Control group $(n=50)$} & \multirow[b]{2}{*}{$p$} \\
\hline & $\mathrm{n}$ & $\%$ & Median & IQR & $\mathrm{n}$ & $\%$ & Median & IQR & \\
\hline Age (year) & & & 51 & $42.75-52.5$ & & & 46 & $38-52$ & 0.19 \\
\hline $\begin{array}{l}\text { Sex } \\
\text { Female }\end{array}$ & 7 & 58 & & & 20 & 52 & & & 0.66 \\
\hline Body mass index $\left(\mathrm{kg} / \mathrm{m}^{2}\right)$ & & & 29.1 & $25.1-32.54$ & & & 28.2 & $23.85-31.2$ & 0.43 \\
\hline Smoking (ever or current) & 6 & 50 & & & 20 & 51 & & & 0.9 \\
\hline Waist circumference $(\mathrm{cm})$ & & & 100 & $90-104.7$ & & & 94 & $87-103$ & 0.4 \\
\hline Fasting glucose (mg/dL) & & & 84.5 & $79.25-105$ & & & 91 & $85-98$ & 0.45 \\
\hline Total cholesterol (mg/dL) & & & 49.5 & $44.5-56.5$ & & & 45 & $39-61$ & 0.68 \\
\hline HDL cholesterol (mg/dL) & & & 120 & $103.5-130.5$ & & & 122 & $97-145$ & 0.31 \\
\hline LDL cholesterol (mg/dL) & & & 122.5 & $92.25-166.25$ & & & 102 & $82-143$ & 0.78 \\
\hline Triglycerides (mg/dL) & & & 197 & $187.25-250$ & & & 196 & $172-225$ & 0.37 \\
\hline $\mathrm{ESR}(\mathrm{mm} / \mathrm{h})$ & & & 15.5 & $8.25-52.75$ & & & 18 & $13-36$ & 0.67 \\
\hline $\mathrm{CRP}(\mathrm{mg} / \mathrm{dL})$ & & & 0.25 & $0.12-0.47$ & & & 0.3 & $0.1-0.7$ & 0.83 \\
\hline
\end{tabular}

ABI: Ankle-Brachial Index; CRP: C-reactive protein; ESR: Erythrocyte sedimentation rate; HDL: High-density lipoprotein; IQR: Interquartile range; LDL: Low-density lipoprotein. 
Table 6. Comparison of disease status among psoriatic arthritis patients with borderline and normal Ankle-Brachial Index values

\begin{tabular}{|c|c|c|c|c|c|c|c|c|c|}
\hline & \multicolumn{4}{|c|}{ Patients with borderline ABI $(n=12)$} & \multicolumn{4}{|c|}{ Patients with normal ABI $(n=39)$} & \multirow[b]{2}{*}{$p$} \\
\hline & $\mathrm{n}$ & $\%$ & Median & IQR & $\mathrm{n}$ & $\%$ & Median & IQR & \\
\hline \multicolumn{10}{|l|}{ Disease duration (year) } \\
\hline Psoriasis & & & 25 & $15-37$ & & & 15 & $7-23$ & 0.03 \\
\hline Psoriatic arthritis & & & 8.5 & $3-16$ & & & 6 & $3-10$ & 0.51 \\
\hline Disease pattern & & & & & & & & & 0.02 \\
\hline Peripheral disease only & 4 & 12.5 & & & 28 & 87.5 & & & \\
\hline Axial disease & 8 & 42.1 & & & 11 & 57.9 & & & \\
\hline Psoriasis Area and Severity Index & & & 2.2 & $0.55-11.5$ & & & 1.2 & $0.1-3.3$ & 0.06 \\
\hline Dactylitis score & & & 0 & $0-1$ & & & 0 & $0-0$ & 0.3 \\
\hline Leeds Enthesitis Index & & & 2.5 & $0.25-4$ & & & 0 & $0-2$ & 0.01 \\
\hline Dermatology Life Quality Index & & & 2 & $0.25-12$ & & & 1 & $0-5$ & 0.33 \\
\hline Health Assessment Questionnaire & & & 0.47 & $0.3-0.83$ & & & 0.25 & $0.05-0.5$ & 0.02 \\
\hline 68 Tender joint count counts & & & 4 & $0.25-19.7$ & & & 2 & $0-4$ & 0.24 \\
\hline 66 Swollen joint count counts & & & 0 & 0-0 & & & 0 & $0-0$ & 0.9 \\
\hline Disease activity & & & & & & & & & $<0.01$ \\
\hline Minimal disease activity & 4 & 11.1 & & & 32 & 88.9 & & & \\
\hline Active disease & 8 & 53.3 & & & 7 & 46.7 & & & \\
\hline Current treatment & & & & & & & & & 0.067 \\
\hline NSAIDs only & 2 & & & & 4 & & & & \\
\hline cDMARDc & 24 & & & & 5 & & & & \\
\hline bDMARDs & 10 & & & & 2 & & & & \\
\hline cDMARDs + bDMARDs & 3 & & & & 1 & & & & \\
\hline
\end{tabular}

ABI: Ankle-Brachial Index; IQR: Interquartile range; NSAIDs: Nonsteroidal anti-inflammatory drugs; cDMARDs: Conventional disease-modifying antirheumatic drugs; bDMARDs: Biologic disease-modifying antirheumatic drugs.

\begin{tabular}{|c|c|c|c|c|c|c|}
\hline & \multirow[b]{2}{*}{$\mathrm{B}$} & \multirow[b]{2}{*}{ SE } & \multirow[b]{2}{*}{$p$} & \multirow[b]{2}{*}{$\operatorname{Exp}(B)$} & \multicolumn{2}{|c|}{$95 \%$ CI for $\operatorname{Exp}(B)$} \\
\hline & & & & & Lower & Upper \\
\hline Age & 0.035 & 0.050 & 0.486 & 1.035 & 0.939 & 1.142 \\
\hline Psoriasis duration & 0.061 & 0.037 & 0.096 & 1.063 & 0.989 & 1.142 \\
\hline Psoriatic arthritis duration & -0.017 & 0.073 & 0.787 & 0.983 & 0.870 & 1.111 \\
\hline Axial vs. peripheral pattern* & 1.130 & 1.445 & 0.229 & 3.096 & 0.490 & 19.548 \\
\hline Active disease vs minimal activity* & 1.841 & 4.660 & 0.031 & 6.306 & 1.185 & 33.561 \\
\hline $\begin{array}{l}p=0.005 \\
\text { Nagelkerke } R^{2}=41.7 \%\end{array}$ & & & & & & \\
\hline
\end{tabular}

regression model. Disease pattern and disease activity were included as a categorical variable. Only disease activity was found as an independent risk factor for borderline ABI (OR 6.306, 95\% confidence interval 1.185 to $33.561, \mathrm{p}=0.031$ ) (Table 7).

\section{DISCUSSION}

The aim of the present study was to assess subclinical atherosclerosis with $\mathrm{ABI}$ in PsA. Patients with PsA had lower ABI than controls matched by age, sex, and traditional CV risk factors. All 
subjects with borderline $\mathrm{ABI}$ were in the patient group. When the literature was reviewed, no study assessing subclinical atherosclerosis with $\mathrm{ABI}$ was found. Another method that has been validated for assessment of subclinical atherosclerosis in rheumatological diseases is the measurement of carotid artery IMT. ${ }^{11}$ There are many studies suggesting that patients with PsA have a higher IMT than healthy controls matched by traditional $\mathrm{CV}$ risk factors. ${ }^{29-31}$ Based on this, our finding is in line with the literature.

Patients with borderline ABI had a significantly longer duration of psoriasis. Borderline $\mathrm{ABI}$ values were also significantly more common in patients with axial disease than in patients with peripheral disease only. This might be related to the disease duration of PsA which was significantly longer in patients with axial disease compared to patients with peripheral disease only. Shang et al. $^{8}$ evaluated ventricular and arterial stiffness in patients with PsA using conventional echocardiography. They found that PsA patients had significantly increased ventricular and arterial stiffness. Longer PsA duration was an independent risk factor for increased left ventricular diastolic elastance. Shen et al. ${ }^{32}$ evaluated coronary arteries in patients with PsA using coronary computed tomography angiography. Patients with PsA had a significantly higher prevalence of overall plaque and the duration of disease was associated with more vulnerable plaques. In addition, there are many studies in the literature showing that the duration of psoriasis alone causes subclinical atherosclerosis. ${ }^{33,34}$ This can be interpreted as the longer exposure of the vessels to chronic inflammation due to prolonged disease duration causing subsequent atherosclerosis.

Patients with active disease had a significantly higher rate of borderline $\mathrm{ABI}$ than patients with MDA. Additionally, disease activity was found as an independent risk factor for borderline ABI. This may suggest that active disease increases the risk of atherosclerosis. Eder et al. ${ }^{35}$ investigated subclinical atherosclerosis with vascular ultrasound of the carotid arteries and measured total plaque area in patients with PsA. In a multivariate regression model adjusted for age and sex, disease activity in PsA was associated with more severe atherosclerosis. Shang et al. ${ }^{36}$ evaluated left ventricular (LV) rotation with the aim to detect impaired LV function in PsA patients. Subclinical impaired myocardial deformation was more common in PsA patients even without $\mathrm{CV}$ risk factors than control subjects. They showed that impaired apical rotation was related to the disease activity score in 28 joints. Moreover, Cheng et al. ${ }^{37}$ investigated whether or not MDA could affect the progression of subclinical atherosclerosis in a prospective cohort study in PsA. Achieving sustained MDA was shown to have a protective effect on plaque progression and also provided less of an increase in mean IMT and total plaque area. On the contrary, Atzeni et $\mathrm{al}^{38}$ found no correlation between subclinical atherosclerosis and disease activity in PsA. Supporting this study, Ramonda et al. $^{39}$ explored the progression of subclinical atherosclerosis in PsA patients treated with anti-tumor necrosis factor alpha agents in a two-year prospective observational study. They showed significant progression despite effective treatment. More research is needed to explain this relationship.

Ankle-Brachial Index is an inexpensive and convenient tool for use in outpatient clinics. The results of this study suggest that the risk of subclinical atherosclerosis will be increased with higher disease activity and longer disease duration. Caution is warranted when interpreting our results. $\mathrm{ABI}$ is a sensitive method for detecting atherosclerosis but it may change in daily activities despite resting before measurement. However, $\mathrm{ABI}$ can be used as a screening tool for subclinical atherosclerosis particularly in patients with active disease and longer disease duration. If any abnormality is detected, further examinations can be undertaken for evaluating atherosclerosis to predict future $\mathrm{CV}$ events.

The present study had a number of limitations. Firstly, all patients were recruited by the principal investigator at a single department. This might have led to selection bias. Secondly, the investigator performing $\mathrm{ABI}$ calculation could not be blinded because of the presence of psoriatic skin plaque in patients. Also, patients were being treated with different drug regimens. Therefore, potential effect of treatments on atherosclerosis might not be excluded.

In conclusion, in this study, PsA patients, even those without traditional $\mathrm{CV}$ risk factors, had lower ABI values compared to healthy controls. The distribution of borderline ABI was 
related to longer disease duration of psoriasis and disease activity. Disease activity was found as an independent risk factor for borderline ABI. We conclude that strict control of atherosclerotic risk factors in patients with PsA is needed, particularly in patients with active disease and longer disease duration.

\section{Declaration of conflicting interests}

The authors declared no conflicts of interest with respect to the authorship and/or publication of this article.

\section{Funding}

The authors received no financial support for the research and/or authorship of this article.

\section{REFERENCES}

1. Moll JM, Wright V. Psoriatic arthritis. Semin Arthritis Rheum 1973;3:55-78.

2. Rudwaleit M, Taylor WJ. Classification criteria for psoriatic arthritis and ankylosing spondylitis/axial spondyloarthritis. Best Pract Res Clin Rheumatol 2010;24:589-604.

3. Kay L, Parry-James J, Walker D. The prevalence and impact of psoriasis in the primary care population in Northeast England. Arthritis Rheum 1999;42(9 Suppl):S299.

4. Shbeeb M, Uramoto KM, Gibson LE, O'Fallon WM, Gabriel SE. The epidemiology of psoriatic arthritis in Olmsted County, Minnesota, USA, 1982-1991. J Rheumatol 2000;27:1247-50.

5. Hochberg MC, Silman AJ, Smolen JS, Weinbatt ME, Wiesman MH, editors. Rheumatology. 6th ed. Philadelphia: Mosby Elsevier; 2014.

6. Jamnitski A, Symmons D, Peters MJ, Sattar N, McInnes I, Nurmohamed MT. Cardiovascular comorbidities in patients with psoriatic arthritis: a systematic review. Ann Rheum Dis 2013;72:211-6.

7. Gladman DD, Ang M, Su L, Tom BD, Schentag CT, Farewell VT. Cardiovascular morbidity in psoriatic arthritis. Ann Rheum Dis 2009;68:1131-5.

8. Shang Q, Tam LS, Sanderson JE, Sun JP, Li $\mathrm{EK}, \mathrm{Yu} \mathrm{CM}$. Increase in ventricular-arterial stiffness in patients with psoriatic arthritis. Rheumatology (Oxford) 2012;51:2215-23.

9. Di Minno MN, Iervolino S, Peluso R, Scarpa R, Di Minno G; CaRRDs study group. Carotid intima-media thickness in psoriatic arthritis: differences between tumor necrosis factor- $\alpha$ blockers and traditional disease-modifying antirheumatic drugs. Arterioscler Thromb Vasc Biol 2011;31:705-12.

10. Contessa C, Ramonda R, Lo Nigro A, Modesti V, Lorenzin M, Puato M, et al. Aterosclerosi subclinica in pazienti con artrite psoriasica: studio caso-controllo. Dati preliminari [Subclinical atherosclerosis in patients with psoriatic arthritis: a case-control study. Preliminary data]. Reumatismo 2009;61:298-305.

11. Kerekes G, Soltész P, Nurmohamed MT, GonzalezGay MA, Turiel M, Végh E, et al. Validated methods for assessment of subclinical atherosclerosis in rheumatology. Nat Rev Rheumatol 2012;8:224-34.

12. Alkaabi JK, Ho M, Levison R, Pullar T, Belch JJ. Rheumatoid arthritis and macrovascular disease. Rheumatology (Oxford) 2003;42:292-7.

13. del Rincón I, Haas RW, Pogosian S, Escalante A. Lower limb arterial incompressibility and obstruction in rheumatoid arthritis. Ann Rheum Dis 2005;64:425-32.

14. Stamatelopoulos KS, Kitas GD, Papamichael CM, Kyrkou K, Zampeli E, Fragiadaki K, et al. Subclinical peripheral arterial disease in rheumatoid arthritis. Atherosclerosis 2010;212:305-9.

15. Guellec D, Bressollette L, Gueguen F, Jousse-Joulin $\mathrm{S}$, Marhadour T, Devauchelle-Pensec $\mathrm{V}$, et al. Is routine ankle-brachial pressure index evaluation useful in rheumatoid arthritis? Joint Bone Spine 2013;80:111-3.

16. Erdozain JG, Villar I, Nieto J, Ruiz-Irastorza G. Peripheral arterial disease in systemic lupus erythematosus: prevalence and risk factors. J Rheumatol 2014;41:310-7.

17. Tziomalos K, Gkougkourelas I, Sarantopoulos A, Bekiari E, Makri E, Raptis N, et al. Arterial stiffness and peripheral arterial disease in patients with systemic lupus erythematosus. Rheumatol Int 2017;37:293-8.

18. Kay SD, Poulsen MK, Diederichsen AC, Voss A. Coronary, Carotid, and Lower-extremity Atherosclerosis and Their Interrelationship in Danish Patients with Systemic Lupus Erythematosus. J Rheumatol 2016;43:315-22.

19. Rachapalli SM, Kiely PD, Bourke BE. Prevalence of abnormal ankle brachial index in patients with primary Sjogren's syndrome. Clin Rheumatol 2009;28:587-90.

20. Fan F, Galvin A, Fang L, White DA, Moore XL, Sparrow $M$, et al. Comparison of inflammation, arterial stiffness and traditional cardiovascular risk factors between rheumatoid arthritis and inflammatory bowel disease. J Inflamm (Lond) 2014;11:29.

21. McKay ND, Griffiths B, Di Maria C, Hedley S, Murray A, Allen J. Novel photoplethysmography cardiovascular assessments in patients with Raynaud's phenomenon and systemic sclerosis: a pilot study. Rheumatology (Oxford) 2014;53:1855-63.

22. Meiszterics Z, Tímár O, Gaszner B, Faludi R, Kehl D, Czirják L, et al. Early morphologic and functional changes of atherosclerosis in systemic sclerosis-a systematic review and meta-analysis. Rheumatology (Oxford) 2016;55:2119-30.

23. Doutrelon C, Skopinski S, Boulon C, Constans J. Macrovascular complications of systemic sclerosis: 
Prospective descriptive Doppler ultrasound study in 20 patients. J Mal Vasc 2016;41:253-9.

24. Johnson SR, Goek ON, Singh-Grewal D, Vlad SC, Feldman BM, Felson DT, et al. Classification criteria in rheumatic diseases: a review of methodologic properties. Arthritis Rheum 2007;57:1119-33.

25. Mumtaz A, Gallagher P, Kirby B, Waxman R, Coates LC, Veale J D, et al. Development of a preliminary composite disease activity index in psoriatic arthritis. Ann Rheum Dis 2011;70:272-7.

26. Calin A, Garrett S, Whitelock H, Kennedy LG, O'Hea J, Mallorie P, et al. A new approach to defining functional ability in ankylosing spondylitis: the development of the Bath Ankylosing Spondylitis Functional Index. J Rheumatol 1994;21:2281-5.

27. Salaffi F, Ciapetti A, Carotti M, Gasparini S, Gutierrez M. Disease activity in psoriatic arthritis: comparison of the discriminative capacity and construct validity of six composite indices in a real world. Biomed Res Int 2014;2014:528105.

28. Rooke TW, Hirsch AT, Misra S, Sidawy AN, Beckman JA, Findeiss LK, et al. 2011 ACCF/AHA Focused Update of the Guideline for the Management of Patients With Peripheral Artery Disease (updating the 2005 guideline): a report of the American College of Cardiology Foundation/American Heart Association Task Force on Practice Guidelines. J Am Coll Cardiol 2011;58:2020-45.

29. Eder L, Zisman D, Barzilai M, Laor A, Rahat M, Rozenbaum M, et al. Subclinical atherosclerosis in psoriatic arthritis: a case-control study. J Rheumatol 2008;35:877-82.

30. Gonzalez-Juanatey C, Llorca J, Amigo-DiazE, Dierssen T, Martin J, Gonzalez-Gay MA. High prevalence of subclinical atherosclerosis in psoriatic arthritis patients without clinically evident cardiovascular disease or classic atherosclerosis risk factors. Arthritis Rheum 2007;57:1074-80.

31. Ibáñez-Bosch R, Restrepo-Velez J, Medina-Malone M, Garrido-Courel L, Paniagua-Zudaire I, Loza-Cortina E. High prevalence of subclinical atherosclerosis in psoriatic arthritis patients: a study based on carotid ultrasound. Rheumatol Int 2017;37:107-12.

32. Shen J, Wong KT, Cheng IT, Shang Q, Li EK, Wong $\mathrm{P}$, et al. Increased prevalence of coronary plaque in patients with psoriatic arthritis without prior diagnosis of coronary artery disease. Ann Rheum Dis 2017;76:1237-44.

33. El-Mongy S, Fathy H, Abdelaziz A, Omran E, George $\mathrm{S}$, Neseem $\mathrm{N}$, et al. Subclinical atherosclerosis in patients with chronic psoriasis: a potential association. J Eur Acad Dermatol Venereol 2010;24:661-6.

34. Yiu KH, Yeung CK, Zhao CT, Chan JC, Siu CW, Tam S, et al. Prevalence and extent of subclinical atherosclerosis in patients with psoriasis. J Intern Med 2013;273:273-82.

35. Eder L, Jayakar J, Shanmugarajah S, Thavaneswaran A, Pereira D, Chandran V, et al. The burden of carotid artery plaques is higher in patients with psoriatic arthritis compared with those with psoriasis alone. Ann Rheum Dis 2013;72:715-20.

36. Shang Q, Tam LS, Sanderson JE, Lee AP, Li EK, $\mathrm{Yu}$ CM. Impaired left ventricular apical rotation is associated with disease activity of psoriatic arthritis. $J$ Rheumatol 2014;41:706-13.

37. Cheng IT, Shang Q, Li EK, Wong PC, Kun EW, Law MY, et al. Effect of achieving minimal disease activity on the progression of subclinical atherosclerosis and arterial stiffness: A prospective cohort study in psoriatic arthritis. arthritis Rheumatol 2019;71:271-80.

38. Atzeni F, Sarzi-Puttini P, Sitia S, Tomasoni L, Gianturco L, Battellino $\mathrm{M}$, et al. Coronary flow reserve and asymmetric dimethylarginine levels: new measurements for identifying subclinical atherosclerosis in patients with psoriatic arthritis. $J$ Rheumatol 2011;38:1661-4.

39. Ramonda R, Puato M, Punzi L, Rattazzi M, Zanon M, Balbi $G$, et al. Atherosclerosis progression in psoriatic arthritis patients despite the treatment with tumor necrosis factor-alpha blockers: a two-year prospective observational study. Joint Bone Spine 2014;81:421-5. 